\title{
PAIS NA CRECHE: A ARTE DO DIÁLOGO ENTRE EDUCADORES E FAMÍLIA*
}

\author{
Ana Maria Orlandina Tancredi Carvalho*
}

\section{$\not{A}$} obra Pais na creche: a arte do diálogo entre educadores e família evidencia que a creche, na Itália - igualmente a outros serviços destinados às crianças de zero a três anos - vem atravessando um dos momentos mais difíceis dos últimos trinta anos, em virtude, basicamente, de sua fragilidade institucional perante o enleamento da legislação. Acrescente-se, ainda, a proposta de antecipação do ingresso das crianças para dois anos e meio à escola da infância, que coloca em xeque diversos fatores, quer em relação ao significado cultural da creche, com seus projetos pedagógicos e organizativos, quer no concernente às propostas educativas destinadas às crianças e suas famílias. Contudo, dificilmente existe, hoje, uma instituição que, como as creches, tenha sido capaz de, em tão pouco tempo e com tanta riqueza, fazer pesquisas, percursos pedagógico-culturais, projetos educativos para crianças, bem como estratégias de apoio às famílias.

A obra, composta por seis capítulos, divide-se em duas partes. $\mathrm{Na}$ primeira, aborda o tema da família, sua identidade e representaçôes, analisando temas como o significado atual de tornar-se família, a representação da paternidade e da maternidade no imaginário coletivo e cinematográfico e o significado do nascimento do bebê para a família. Na segunda parte, evidencia o crescimento da criança para além do âmbito familiar, enfatizando a creche, a relação entre educadores e família, bem como as perspectivas para essas duas instituiçóes.

\footnotetext{
* Resenha do livro L'arte del dialogo tra educatori e famiglia, de Laura Restuccia Saitta e Lucca Genitori al Nido Saitta (Milano, Italia: La Nuova Itália, 2002).

** Doutoranda pela Faculdade de Educação da Universidade Estadual de Campinas (unicamp), professora do Centro de Educação da Universidade Federal do Pará (UfPa) e integrante do "Grupo de Estudos e Pesquisas em Educação e Diferenciação Sócio-Cultural" (GEPEDISC) da UNICAMP.E-mail: anatanc@ufpa.br
} 
O olhar atento que a obra dirige à participação familiar no espaço educativo das creches, em seus múltiplos aspectos, constitui excelente trabalho de reflexão aos que, por diferentes motivos, ocupam-se da infância, em particular professores(as) da Educação Infantil.

Ser pai e ser mãe não é algo natural. Torna-se pai e mãe! Este vir a ser implica um projeto de vida que, para além das alegrias e gratificações, implica novos enredos para e na vida do casal, enredos que, freqüentemente, impóem-se de forma imprevisível, dando lugar a novas experiências e, desse modo, a novas respostas. Enredos, experiências e respostas constitutivos quer da possibilidade da continuidade, quer da mudança de padrões de comportamentos e das relações estabelecidas entre sujeitos e instituições envolvidos no trato da criança.

Há muito, nas sociedades ocidentais contemporâneas, já não se reduz o conceito de maternidade a um papel, anteriormente, inevitável para a mulher. O papel da maternidade tem sido exercido mais conscientemente e em virtude das experiências de cada indivíduo (tanto homens, quanto mulheres) vai se reconfigurando. Tornar-se pai e mãe é, também, um processo carregado de variadas emoções: significa atravessar uma fase da vida, constituída por mudanças relevantes, possibilitando a construção de uma nova identidade: a de ser pai e mãe, o que representa uma dimensão diferente da vida adulta, na qual o pai e a mãe devem ativar novos recursos, novos registros relacionais e cognitivos, novas modalidades de organização. E como as identidades paternas e maternas são representadas nos filmes e no imaginário coletivo? Esse tipo de análise é bastante extensa na obra, tanto em relação aos filmes americanos, como italianos. Nesta resenha, destacaremos apenas um filme, que julgamos como um divisor de águas no que concerne à concepção dos papéis de pai e mãe na relação com a criança. Trata-se de Kramer versus Kramer, interpretado por Dustin Hoffman, que narra uma original história familiar, em que o marido, abandonado pela esposa, vê-se às voltas com o cuidar do filho. Passado o momento inicial de angústia, o pai se sente, perfeitamente gratificado nessa tarefa - aliás, mais do que no seu trabalho - a ponto de recorrer ao tribunal para garantir a guarda do filho, quando a mãe retorna em busca de reassumir seu papel de mãe.

Por que considera-se este filme como um divisor de águas? Porque, pela primeira vez, o cinema propõe um novo modelo paterno, aquele que cria e educa o filho. Um modelo, decididamente, fora dos cânones tradicionais. 
A partir do final da década de 1970, a mulher ocidental começa a forjar sua nova identidade. Reivindica autonomia na atividade profissional, declarando aberto conflito à sociedade patriarcal e ao homem - não ao homem isolado, com quem se relaciona, mas ao homem tomado na acepção emblemática de uma certa configuração socioeconômica estruturando sua consciência de gênero e construindo um "nós" coletivo, no interior do qual a mulher recusa-se a assumir o único papel que, até então, lhe fora reservado: o de ser mãe. Dessa forma, ser mãe torna-se apenas um dos horizontes da vida feminina. Estas transformações possibilitam à mulher, cada vez mais, decidir ter ou não filhos ou filhas.

A obra destaca, ainda, as transformações em relação às figuras paterna e materna ocorridas na atual configuração societal, evidenciando quão complexas são as situações familiares e auxiliando a compreender de que modo o nascimento de um filho, ainda que muito desejado e fruto de uma intensa relação afetiva, pode colocar duras provas à estabilidade e à preservação do casal. $\mathrm{O}$ desconforto ao voltar para casa, o impacto com a vida cotidiana, particularmente cansativa, um sentimento de vazio, a ambivalência em relação ao apoio familiar disponível são experiências que, freqüentemente, os dois membros do casal, ainda que de forma diferente, enfrentam. Recorrer aos parentes, em particular aos avós, é uma prática ligada à qualidade do relacionamento existente com a família de origem: é difícil, não raras vezes, instituir uma distância justa que circunscreva eventuais intromissões dos avós e estabeleça limites recíprocos. Essa é uma vivência comum a todos e todas que estão às voltas com o nascimento de uma criança. Todavia, torna-se necessário encontrar soluções e reencontrar o equilíbrio por meio de redes de apoio, sejam elas de ordem familiar ou social. No que diz respeito a redes de apoio de natureza social, lugar importante ocupam as creches e os serviços integrativos oferecidos aos bebês, que, no contexto italiano, são de alta qualidade.

A introdução da criança na creche pode ser considerada um rito de passagem, que marca a primeira verdadeira separação da criança de seu ambiente familiar e sua entrada no universo social. Trata-se de um momento inicial de exercício da autonomia para ela, que vai aprendendo a governar-se. Evidentemente, isso não acontece repentinamente: é um processo de apego e separação. Alguns aspectos, ainda, são importantes destacar no que concerne à vida na creche: a amizade que nasce entre as crianças inicia um processo de disposição social, que está na base da colaboração e da comunicação; esse novo relacionamento for- 
nece à criança a possibilidade de ela se conhecer e conhecer os outros e o mundo.

Estudos recentes nas creches confirmam que a interação entre pares - desenvolvendo-se em uma relação de iguais - comporta, no plano cognitivo, uma diversidade de informaçôes e conhecimentos, bem como, no plano afetivo, enfrentamentos e possibilidades de identificações diversas. Tais estudos, realizados por meio de observações, demonstram que entre as crianças existe colaboração, interesse pelos coetâneos, curiosidade intelectual e capacidade de compartilhar a atenção.

As creches e os demais serviços integrados destinados aos três primeiros anos de vida da criança, em virtude da grande experiência de relacionamento, podem fornecer instrumentos importantes no sentido de interpretar a cotidianidade familiar, pois trabalhadores e trabalhadoras das creches já elaboraram sofisticadas competências, tornando-se hábeis no que temos chamado de "arte do diálogo" com a família.

Qual é, contudo, o projeto político-pedagógico da creche? É importante indagar que tipo de proposta pretendemos compartilhar com os pais em relação às crianças? A partir de quais objetivos articula-se o projeto político-pedagógico? Qual criança imaginamos? Para qual criança organizamos nossa intervenção educativa?

A construção da identidade representa o fio condutor nucleador de todas as atividades do projeto político-pedagógico da creche destinada a organizar na criança uma troca permanente consigo mesma e entre si e os outros, adultos, coetâneos e com a imagem de si transmitida por estes interlocutores. Tudo isso deve estar inserido em um contexto maior que tenha como objetivo o bem-estar da criança, ou melhor, "o estar bem no mundo". Isso tudo, ancorado na realidade, referenciado no passado, permitindo a elaboração e vivência de instrumentos de leitura e compreensão do presente e projeção de um futuro, que se paute em princípios éticos diversos dos que têm regulado o habitus contemporâneo.

Essa perspectiva requer dos educadores, mediante processos formativos, um aprofundamento teórico que permita analisar, elaborar e traduzir, operacionalmente, a partir de estratégias educativas e organizacionais, o conceito de identidade.

Qual o papel do ambiente (espaço e tempo), o papel das experiências, de adultos e crianças, dos jogos, das atividades (os percursos 
cognitivos)? Qual o contexto em que os(as) professores(as) da creche desenvolvem seu trabalho?

O contexto em que atua o profissional da creche é representado por um trabalho coletivo, uma comunidade educativa, um espaço predominantemente aberto, que dirige a creche, pedagógica e administrativamente, mediante o conjunto de diferentes figuras profissionais (educadores, pessoas de apoio e cozinheiras), atuando em distintos trabalhos, requerendo paridade e colaboração nesse fazer.

E qual é a identidade do(a) professor(a) de creche? Importa frisar que, no panorama italiano, é um profissional com características bastante anômalas e que, muito embora possua uma riqueza de reflexões teóricas em torno da creche, ressente-se, ainda, da falta de um perfil da profissão que lhe dê um caráter homogêneo. Pode-se, porém, assegurar que este perfil não corresponde aos modelos familiares ou escolares.

E qual a especificidade do trabalho do(a) professor(a) de creche? Este pode ser resumido em duas palavras: cuidar e educar.

$\mathrm{O}$ que significa cuidar? $\mathrm{O}$ trabalho de cuidar, realizado pelo(a) professor(a) de creche, é complexo e requer habilidades de ordem psicológica, organizativa e estratégica. Requer rapidez de decisão, capacidade de expressão, de combinação de recursos, da disponibilidade, representada pelo sorriso e pelo acolhimento e, ao mesmo tempo, agilidade para deslocar-se de um lugar a outro e uma capacidade singular para escutar, sentir e compartilhar com o outro.

Tudo isso oferece-nos o quadro de uma gestão social que não pode ser considerada uma simples proposta de organização, uma forma metodológica de gestão: é uma escolha de fundo, uma concepção de prática educativa que pressupõe uma atitude mental, um estilo de trabalho, um modo diferente de relacionamento entre as pessoas e entre estas e as instituições. Esta prática, portanto, não pode ser vivenciada como uma obrigação moral, profissional, ou um ritual.

Trata-se de uma obra que, ao lado das questões teóricas suscitadas, contextualiza historicamente o trabalho com as crianças de zero a três anos, na Itália. 